\title{
CINEMATIC REALISM: A DEFENCE FROM PLATO TO GAUT
}

\section{Rafe McGregor}

The purpose of this paper is to defend a particular kind of cinematic realism, anti-illusionism, which is the thesis that cinematic motion is real. Following a brief introduction to realism and cinema in $\S 1$, I analyse Berys Gaut's taxonomy of cinematic realism and define antiillusionism in $\S 2$. $\S 3$ contrasts the anti-illusionist theories of Gregory Currie and Trevor Ponech with the illusionist theories of Andrew Kania and Gaut. I reconceptualise the debate in terms of Tom Gunning’s cinematic animation in $\S 4$, focusing on the question of cinematic singletons. In $\S 5$ I argue that cinematic singletons both exist and undergo objective displacement - and thus for anti-illusionism. I conclude, in $\S \S 6-7$, with responses to potential objections to my argument from Kania and Gaut.

\section{Cinematic Reality}

André Bazin is probably the best-known film theorist identified with realism and was one of the founding editors of the influential Cahiers du Cinéma (Notebooks on Cinema) in 1951. After his death in 1958 four volumes of his film criticism were collected in a series entitled What is Cinema? Bazin wrote of 'true realism', 'pseudorealism', 'expressionist realism', 'impressionist realism', 'ontogenetic realism', 3 'integral realism', 'poetic realism', 'Italian

\footnotetext{
${ }^{1}$ André Bazin, What is Cinema? Volume I, trans. Hugh Gray (Los Angeles: University of California Press, 1967 [1958-1965]), 12.

${ }^{2}$ Bazin, What is Cinema? 16.

${ }^{3}$ Bazin, What is Cinema? 19.

${ }^{4}$ Bazin, What is Cinema? 21.

${ }^{5}$ Bazin, What is Cinema? 29.
} 
neorealism', ' 'photographic realism', 'realism of subject matter', 'realism of expression', 'realism of space', ${ }^{8}$ and 'absolute realism'. ${ }^{9}$ He nonetheless associated realism in the arts including cinematic art - straightforwardly with resemblance and championed what is now known as the deep focus style over the montage style on the basis of the former's 'integral realism', i.e. its ability to reproduce reality as it is rather than reality as it is interpreted by the director. ${ }^{10}$ Siegfried Kracauaer is acknowledged as being responsible for the first systematic and ultimately the most comprehensive realist film theory, which is set out in Theory of Film: The Redemption of Physical Reality, first published in 1960. Kracauer wrote of 'naïve realism', ${ }^{11}$ 'camera-realism', ${ }^{12}$ 'cinematic realism', ${ }^{13}$ 'surrealism', ${ }^{14}$ 'social realism', ${ }^{15}$ and 'neorealism'. ${ }^{16}$ Like Bazin's, Kracauer's realism was based on the photographic medium of the cinematic art form. Kracauer's cinematic realism was in fact camera-realism and his clearest definition of the concept is presented in his definition of the true film artist, who may be imagined as a man who sets out to tell a story but, in shooting it, is so overwhelmed by his innate desire to cover all of physical reality - and also by a feeling that he must cover it in order to tell the story, any story, in cinematic terms that he ventures ever deeper into the jungle of material phenomena in which he risks becoming irretrievably lost if he does not, by virtue of great efforts, get back to the highways he has left. ${ }^{17}$

\footnotetext{
${ }^{6}$ Bazin, What is Cinema? 37.

${ }^{7}$ Bazin, What is Cinema? 103.

${ }^{8}$ Bazin, What is Cinema? 112,

${ }^{9}$ Bazin, What is Cinema? 130.

${ }^{10}$ Bazin, What is Cinema? 21.

${ }^{11}$ Siegfried Kracauer, Theory of Film: The Redemption of Physical Reality (New York: Oxford University Press, 1960), 7.

12 Kracauer, Theory of Film, 32.

${ }^{13}$ Kracauer, Theory of Film, 155.

${ }^{14}$ Kracauer, Theory of Film, 177.

${ }^{15}$ Kracauer, Theory of Film, 208.

${ }^{16}$ Kracauer, Theory of Film, 274.

${ }^{17}$ Kracauer, Theory of Film, 255.
} 
Bazin and Kracauer were (1) concerned exclusively with the photographic aspect of film and (2) placed the emphasis on reproduction (of reality as it is) over representation (of reality as it is interpreted by the director). The former opens the theorists up to the criticisms of medium specificity and the latter to what Edward Hudlin calls 'a naïve acceptance of the doctrines of the "innocent eye" and the "artless style"" ${ }^{18}$

Both the phenomenological-hermeneutic and analytic traditions were relatively slow to turn their attention to film as the subject of philosophical reflection. Stanley Cavell's The World Viewed: Reflections on the Ontology of Film (1971) was a precursor to Gilles Deleuze's Cinéma I: L'image-mouvement (Cinema I: The Movement-Image, 1983) in the former and Noël Carroll's Philosophical Problems of Classical Film Theory and Mystifying Movies: Fads and Fallacies in Contemporary Film Theory (both published in 1988) in the latter. Deleuze completed his philosophy of film with Cinéma II: L'image-temps (Cinema II: The Time-Image) in 1985, but it was ten more years until the publication of the first systematic cinematic aesthetics, Gregory Currie's Image and Mind: Film, Philosophy, and Cognitive Science. Currie defines his philosophy of film as realist on the basis of his stance on three theses: illusionism, transparency, and likeness. ${ }^{19}$ There are two types of illusionism associated with film, cognitive and perceptual, and Currie rejects both. He first dismisses the 'Imagined Observer Hypothesis', the claim that the viewer believes that he or she occupies the position of the camera and is therefore present in the story. ${ }^{20} \mathrm{He}$ then dismisses the weaker illusionist thesis, which is that the movement of images onscreen is illusory. ${ }^{21}$ Transparency was a term used by Kendall Walton to describe what Currie calls the

\footnotetext{
${ }^{18}$ Edward W. Hudlin, "Understanding the Realist Tendency in Cinema," Journal of Aesthetic Education 14 (1980), 81-91: 81 .

${ }^{19}$ Gregory Currie, Image and Mind: Film, Philosophy, and Cognitive Science (Cambridge: Cambridge University Press, 1995), 19-22.

${ }^{20}$ Currie, Image and Mind, 167. Currie also refers to this hypothesis as imagining seeing.

${ }^{21}$ Currie, Image and Mind, 28-47.
} 
'Presentation Thesis', the idea that photographs present rather than represent their subjects. ${ }^{22}$ Both Currie's rejection of transparency and perceptual illusionism are controversial and are discussed below. Currie endorses likeness as central to cinematic ontology and argues that: 'Likeness is a coherent thesis, and that it is possible to achieve a considerable degree of this kind of realism in film. ${ }^{23}$ Currie's cinematic realism remained dominant for over a decade in cinematic aesthetics despite his focus on photography and his failure to anticipate the significance of the developments in digital technology that were taking place at the end of the century. $^{24}$

\section{Cinematic Realism}

In A Philosophy of Cinematic Art, Berys Gaut identifies three different categories of motion picture: object-generated, handmade, and mechanically-generated. ${ }^{25}$ Object-generated motion pictures have existed since at least the tenth century CE, in the form of Indonesian and Chinese shadow puppet plays. Handmade motion pictures include flip-books, magic lanterns, the thaumatrope, the phenatakistocope, the zoetrope, the choreutoscope, and the praxinoscope (all of which predate mechanically-generated film). Mechanically-generated motion pictures began with Edison's kinetoscope and the Lumière cinématographe - both of which used film stock - and the category includes subsequent electronic and digital developments. My interest is in cinematic representation broadly construed, i.e. as including all three of Gaut's categories of cinematic art, a position I have defended elsewhere. ${ }^{26} \mathrm{He}$

\footnotetext{
${ }^{22}$ Currie, Image and Mind, 48. See also: Kendall Walton, “Transparent Pictures: On the Nature of Photographic Realism," Critical Inquiry 11 (1984), 246-277.

${ }^{23}$ Currie, Image and Mind, 79.

${ }^{24}$ This is not to underestimate the contribution of Carroll to cinematic aesthetics, a field in which he was both the first and the most prolific author. Most of Carroll's contributions have been articles and essays, however, and his best-known work on film has been channeled into other topics, such as The Philosophy of Horror, or Paradoxes of the Heart (1990) and A Philosophy of Mass Art (1998).

${ }^{25}$ Berys Gaut, A Philosophy of Cinematic Art (Cambridge: Cambridge University Press, 2010), 6-10.

${ }^{26}$ See: Rafe McGregor, A New/Old Ontology of Film, Film-Philosophy 17 (2013), 265-280.
} 
sets out a taxonomy of seven distinct kinds of realism that are relevant to all cinematic representation. The first five are:

(a) Content realism: the characters, settings, and action in a fictional representation are of a kind that exists in reality. ${ }^{27}$

(b) Photorealism: the animated image of a character, setting, or action in a representation is indiscriminable from a photographic image of the character, setting, or action. ${ }^{28}$

(c) Ontological realism: a photographic image has a causal rather than intentional relation to that which is represented because the representation is created by the capture of light waves emanating from that which is represented. ${ }^{29}$

(d) Epistemic realism: a photographic image offers strong although not conclusive evidence that that which is represented existed at the time the photographic representation was created..$^{30}$

(e) Perceptual realism: the characters, settings, and action in a representation look (and sound) like their counterparts in reality. ${ }^{31}$

Content realism concerns what is represented. Photorealism and perceptual realism are both aspects of formal realism and describe how the content is represented. Ontological and epistemic realism move beyond aesthetic concerns with realism to the metaphysical and epistemic respectively. When one compares cinematic representation to other, similar, modes of representation - such as pictorial, photographic, and theatrical - in terms of (a) to (e), it is obvious that cinematic representation has the greatest scope for realism. Only photographic representations can be realist in all five senses, but cinematic representations have a much

\footnotetext{
${ }^{27}$ Gaut, Cinematic Art, 61-62.

${ }^{28}$ Gaut, Cinematic Art, 66-67.

${ }^{29}$ Gaut, Cinematic Art, 67-68.

${ }^{30}$ Gaut, Cinematic Art, 68-71.

${ }^{31}$ Gaut, Cinematic Art, 71-77.
} 
greater scope for (e) because they can represent both the movement and the sound of that which is represented.

Gaut's sixth kind of realism is transparency, which I mentioned in $§ 1$ in my summary of Currie and which continues to be the subject of extensive debate in philosophy. The idea that a photograph is transparent rather than opaque - that it presents rather than represents that at which the camera is pointed - is encapsulated in both Bazin and Kracauer's cinematic realism and was recognised by film theorist Rudolf Arnheim when he claimed that 'the film is on its way to the victory of wax museum ideals over creative art. ${ }^{, 32}$ Roger Scruton developed this notion to claim that photography - and therefore film - was not a representational art form because a photograph is a reproduction of reality, 'merely a simulacrum of its subject. ${ }^{, 33}$ As previously noted, Walton refined Bazin's idea to claim that photographs were literally transparent, that 'we see the world through them.' ${ }^{34}$ Dominic Lopes has a more radical view, arguing that transparency is 'the key to explaining experiences of pictures of all kinds', i.e. that both handmade and photographic pictorial representations are transparent. ${ }^{35}$ Gaut offers a concise and convincing response to Lopes, Walton, Scruton, and the film theorists that preceded them, defending the claim that 'there is a simple and intuitively plausible necessary condition for when we really see something: we do so only when rays of light from the object pass directly into our eyes. ${ }^{, 36}$ As such, contra Lopes, all pictorial representations (whether handmade or photographic) are opaque rather than transparent and as cinematic representation is representation by means of displays of moving pictures, all cinematic representations are opaque.

\footnotetext{
${ }^{32}$ Rudolf Arnheim, Film as Art (Berkeley: University of California Press, 1957), 8.

${ }^{33}$ Roger Scruton, "Photography and Representation," Critical Inquiry 7 (1981), 577-603: 592.

${ }^{34}$ Walton, "Transparent Pictures," 251.

${ }^{35}$ Dominic McIver Lopes, Understanding Pictures (Oxford: Clarendon Press, 1996), 180.

${ }^{36}$ Gaut, Cinematic Art, 97.
} 
Gaut's seventh kind of realism is illusionism, but as illusionism is an un-, anti-, or nonrealistic conception in the context of cinematic representation I shall employ Trevor Ponech's 'anti-illusionism' instead. ${ }^{37}$ Illusionism is the thesis that 'films standardly create an illusion in the minds of their spectators'. ${ }^{38}$ I shall therefore define anti-illusionism as follows:

Anti-illusionism: cinematic representations do not standardly create an illusion in the minds of their spectators.

Gaut notes that two types of illusion are in question, cognitive and perceptual. Cognitive illusions concern the belief of the spectator and in film theory usually include one or both of the beliefs that (i) the fictional characters, settings, and actions are real and (ii) that the spectator is in their presence. ${ }^{39}$ As mentioned in $\S 1$, Currie provides a convincing refutation of the cognitive or strong illusionist thesis. Perceptual illusions may - but need not - involve false beliefs, as Gaut states: 'I may know in the Müller-Lyer illusion that the two lines are of the same length, yet my experience represents them as being of different lengths. ${ }^{40}$ In cinematic representation, the illusion in question is the movement of pictures. In Gaut's contribution to the Philosophical Studies symposium on Image and Mind, he offered broad support of Currie's realism, understood as the acceptance of likeness and rejection of transparency and illusionism. ${ }^{41}$ Gaut has subsequently developed his view and maintains that 'the apparent movement of still images in all kinds of cinema other than object-generated ones (shadow plays) is illusory. ${ }^{42}$ The issue of whether the moving pictures in a cinematic representation actually move has generated sporadic debate in the last twenty years, with

\footnotetext{
37 Trevor Ponech, "External Realism about Cinematic Motion,” British Journal of Aesthetics 46 (2006), 349368: 354.

${ }^{38}$ Gaut, Cinematic Art, 62.

${ }^{39}$ Gaut, Cinematic Art, 62.

${ }^{40}$ Gaut, Cinematic Art, 64.

${ }^{41}$ Berys Gaut, "Imagination, Interpretation, and Film," Philosophical Studies 89 (1998), 331-341: 331.

${ }^{42}$ Gaut, Cinematic Art, 64.
} 
Gaut and Andrew Kania in support of illusionism and Currie, Ponech, and myself in opposition. $^{43}$

\section{Cinematic Illusion}

There are at least two reasons why the illusionism versus anti-illusionism debate is unsatisfactory as it stands: (a) conflation between the denotation and connotation of "illusion" and (b) its piecemeal nature. The first of these is illustrated by the original appearance of cinematic representation in philosophy, in Plato's Republic. Plato explains his theory of forms by means of the simile of the sun, the analogy of the divided line, and the allegory of the cave. ${ }^{44}$ Of these three, the allegory of the cave is the most comprehensive, distinguishing the four ontological categories of representations, objects, concepts (forms), and the first cause (form of the good). The allegory begins as follows:

Imagine human beings living in an underground, cavelike dwelling, with an entrance a long way up, which is both open to light and as wide as the cave itself. They've been there since childhood, fixed in the same place, with their necks and legs fettered, able to see only in front of them, because their bonds prevent them from turning their heads around. Light is provided by a fire burning far above and behind them. Also behind them, but on higher ground, there is a path stretching between them and the fire. Imagine that along this path a low wall has been built, like the screen in front of puppeteers above which they show their puppets. [...] Then also imagine that there are people along the wall, carrying all kinds of artifacts that project above it - statues of people and other animals, made out of stone, wood, and every material. And, as

\footnotetext{
${ }^{43}$ See: Andrew Kania, "The Illusion of Realism in Film," British Journal of Aesthetics 42 (2002), 243-258 \& Rafe McGregor, "Cinematic Realism Reconsidered," Polish Journal of Philosophy VI (2012), 57-68. ${ }^{44}$ Plato, Republic, trans. G.M.A. Grube \& C.D.C. Reeve, in Plato: Complete Works, ed. John M. Cooper (Indianapolis: Hackett, 1997), 507b-509c, 509d-511e \& 514a-520a.
} 
you'd expect, some of the carriers are talking, and some are silent. [...] Do you suppose, first of all, that these prisoners see anything of themselves and one another besides the shadows that the fire casts on the wall in front of them? [...] And if they could talk to one another, don't you think they'd suppose that the names they used applied to the things they see passing before them? [...] And what if their prison also had an echo from the wall facing them? Don't you think that they'd believe that the shadows passing in front of them were talking whenever one of the carriers passing along the wall was doing so? [...] Then the prisoners would in every way believe that the truth is nothing other than the shadows of those artifacts. ${ }^{45}$

The prisoners in the cave are at the lowest epistemic level because they believe that the representations (shadows) are real when both representations and the objects used to create them lack the reality of concepts (forms). Crucially, the prisoners are being deceived by the shadow play they are watching and this pejorative sense of illusion has re-emerged in the contemporary debate.

Currie notes the distinction between the real, apparent, and illusory (and argues that cinematic motion is apparent). ${ }^{46}$ Gaut introduces the notion of deception when he states that apparent motion in cinema (object-generated excluded) is a perceptual illusion that may also be a cognitive illusion because some of the audience may believe that the pictures are actually moving. ${ }^{47}$ Tom Gunning is explicit on the issue: 'I say producing the perception of motion, rather than the illusion of motion, which carries a tone of denigration and a distrust of perception. ${ }^{48}$ Having identified the type of realism I shall be discussing as anti-illusionism in $\S 2$, I shall clarify that the opposing thesis carries no connotation of denigration or distrust

\footnotetext{
${ }^{45}$ Plato, Republic, 514a1-514c2.

${ }^{46}$ Currie, Image and Mind, 47.

${ }^{47}$ Gaut, Cinematic Art, 64.

48 Tom Gunning, "The Paradox of Mechanical Motion: Bergson's Critique of the Cinématographe and the Paradox of Mechanical Motion," The Moving Image 14 (2014), 1-9: 3-4.
} 
and that illusionism about cinematic representation could be considered very similar to E.H. Gombrich's thesis about pictorial representation in Art and Illusion. Referring to a cartoon by “Alain” (Daniel Brustlein) in The New Yorker Magazine, Gombrich writes:

What Alain's Egyptian boys had to learn before they could create an illusion of reality was not to "copy what they saw" but to manipulate those ambiguous cues on which we rely in stationary vision till their image was indistinguishable from reality. ${ }^{49}$

It may well be the case that movement is not represented by copying movement in nature, but by carefully manipulating the vision of the audience until the represented movement becomes indistinguishable from natural movement, an illusion of reality that need not involve any kind of cognitive deception.

The second problem with the debate thus far is its piecemeal nature, which takes two separate forms. First, Kania's paper is a response to Currie and Ponech's paper a response to Kania and Currie. My paper discusses all three, but not Gaut and Gaut discusses only Currie (albeit with a brief mention of Kania). No one has taken all four of the main approaches - Currie, Kania, Ponech, and Gaut - into account in resolving the debate. Second, the debate is not unified with respect to the definition of cinema employed. Gaut discusses all three categories - object-generated, handmade, and mechanically-generated - but the rest of the contributors have been concerned exclusively with mechanically-generated cinema. Compared to the debate about transparency the debate about illusionism is neither sustained nor consistent and consequently remains unresolved. In the remainder of this paper, I shall provide an antiillusionist solution to the problem that takes all four approaches and all three categories of cinema into account.

\footnotetext{
${ }^{49}$ E.H. Gombrich, Art and Illusion: A Study in the Psychology of Pictorial Representation, Sixth Edition (London: Phaidon, 2014 [1959]), 24.
} 


\section{Anti-Illusionism}

As Ponech points out, illusionism is by far the dominant view and, as Kania points out, Currie does not offer a positive argument for his anti-illusionism, merely placing the burden of proof on the illusionist. ${ }^{50}$ Currie's burden of proof claim and his subsequent comparison of cinematic motion with the Müller-Lyer illusion are not articulated with a great deal of conviction in Image and Mind, but Ponech sets out Currie's position in a less conjectural manner. ${ }^{51}$ Ponech defines a genuine illusion as an appearance that is subject to independent verification. ${ }^{52}$ This is easily done for the Müller-Lyer illusion by measuring the two lines with a ruler or more sophisticated instrument, but not - according to Currie - for cinematic motion. Kania's response to Currie is to argue precisely that cinematic motion is subject to independent measurement and verification by means of slowing down the speed of projection of the cinematic representation:

As one begins to see the frames being replaced by one another, and the apparent motion disappearing and reappearing with changes in the speed of projection, one sees that (or rather how, since I think almost no one believes the images are really moving) the motion is illusory. ${ }^{53}$

Kania employs an entertaining example of John Wayne's distinctive stride in a shot of The Searchers to claim that slowing down the speed of the projection reveals that cinematic motion is unlike the 'garden-variety motion possessed by such things as my bicycle as I ride to school' and therefore illusory. ${ }^{54}$

\footnotetext{
${ }^{50}$ Ponech, "External Realism," 350; Kania, "Illusion of Realism," 245.

${ }^{51}$ See: Currie, Image and Mind, 38 \& 43-44.

52 Ponech, "External Realism," 352.

${ }^{53}$ Kania, "Illusion of Realism," 246.

${ }^{54}$ Kania, "Illusion of Realism," 247.
} 
Ponech responds to Kania by claiming that slowing down the projection speed is not equivalent to measuring the Müller-Lyer lines because the question concerns cinematic movement, i.e. the movement of images in the cinematic experience, and the viewer who sees the frames being replaced by one another is no longer having a cinematic experience. 'All we thereby glimpse is a quasi-cinematic display momentarily deprived of one of its ontological primitives.' 55 The difference between a cinematic display and quasi-cinematic display recalls Deleuze on the movement-image. Deleuze, who - like Ponech - is concerned with mechanically-generated traditional film, distinguishes the photogramme from the movement-image as follows:

Cinema proceeds with photogrammes - that is, with immobile sections - twenty-four images per second (or eighteen at the outset). But it has often been noted that what it gives us is not the photogramme: it is an intermediate image, to which movement is not appended or added; the movement on the contrary belongs to the intermediate image as immediate given. [...] In short, cinema does not give us an image to which movement is added, it immediately gives us a movement-image. It does give us a section, but a section which is mobile, not an immobile section + abstract movement. $^{56}$

In “Cinematic Realism Reconsidered”, I developed Ponech's claim about a quasi-cinematic display to argue that there are necessary conditions for a cinematic experience and that those conditions produce a response-dependent rather than illusory motion of images on the screen. ${ }^{57}$ That argument took the existence of reception conditions for the experience of works of art as a premise and cannot therefore be employed here as I am presently concerned with all cinematic representations not just the subset of those cinematic representations that

\footnotetext{
${ }^{55}$ Ponech, "External Realism," 359.

${ }^{56}$ Gilles Deleuze, Cinema I: The Movement-Image, trans. Hugh Tomlinson \& Barbara Habberjam (London: Continuum, 2005 [1983]), 2-3.

${ }^{57}$ McGregor, "Cinematic Realism Considered," 63-65.
} 
are also works of cinematic art. ${ }^{58}$ Ponech's response to Kania is nonetheless convincing if one considers the positive argument he makes for cinematic motion.

Ponech is concerned with a 'class of artefacts which involve structurally and functionally coupling an informative projectable with an exhibition device' and distinguishes a visual display from both the display format and the screen. ${ }^{59}$ The first distinction is similar to the rejection of medium essentialism and his focus is on the visual display, which is 'our proximal perceptual object' ${ }^{60}$ The visual display has two essential features, pixels and stroboscopic motion. Pixels are 'spatially-temporally separated points of light arrayed on a light diffusing surface' and stroboscopic motion 'the display's temporal frequency [...] the continuous transformations a display undergoes, transformations partly constitutive of it. ${ }^{91}$ Stroboscopic motion distinguishes mechanically-generated motion pictures from other means of representation (including handmade motion pictures) and generates singletons. ${ }^{62} \mathrm{~A}$ singleton is a visible structure standing out from its background and other such structures in its vicinity. As such it is one perceptual target, perhaps among many, present in the display space [...] it is not an abstract entity but a tangible object of experience. Viewers are in sensory contact with it and have perceptual representations which are about it. ${ }^{63}$

Singletons are real and are not reducible to their constituent pixels or to any part of the visual display. ${ }^{64}$

\footnotetext{
${ }^{58} \mathrm{My}$ argument was also problematic in: (a) being overly prescriptive in restricting these necessary conditions to projection at the speed of twenty-four frames per second and (b) failing to provide an account of apparently similar, but non-artistic cinematic representations.

${ }^{59}$ Ponech, "External Realism," 356.

${ }^{60}$ Ponech, "External Realism," 356.

${ }^{61}$ Ponech, "External Realism," 356 \& 357.

${ }^{62}$ Ponech, "External Realism," 359-360.

${ }^{63}$ Ponech, "External Realism," 360.

${ }^{64}$ Ponech, "External Realism," 362.
} 
The concept captures the intent of Currie's claims that: (a) the cinematic 'image is a particular thing, and a thing that moves';65 (b) 'cinematic images are real objects, reidentifiable across time and occupying different positions at different times during the viewing of the shot'; ${ }^{66}$ and (c) cinematic images are 'images of reidentifiable physical objects' or, more simply, a cinematic image is a 'particular reidentifiable thing' ${ }^{67}$ Ponech then returns to Kania's definition of garden-variety motion, which requires: (i) an object and (ii) the occupation by that object of "contiguous spatial locations at contiguous moments in time. ${ }^{98}$ He claims that a singleton - for example, $W$, the cinematic image of John Wayne in The Searchers - is an object in the relevant (perceptual) sense and that this object undergoes 'continuous stroboscopic displacement', i.e. objective displacement within the visual display. The retrospective introduction of the concept of singletons into the debate yields the following positions:
(A) Singletons are subjectively real and their motion is objectively real (Ponech).
(B) Singletons and their motion are subjectively real (Currie).
(C) Singletons and their motion are illusory (Kania).

\section{Cinematic Animation}

Before returning to Kania's objection and addressing Gaut's objection, I want to bring the above three positions into line with Gaut, i.e. consider all three categories of cinematic representation. Ponech's singletons are generated by stroboscopic motion - by the stroboscopic motion of pixels - and stroboscopic motion is dependent upon the propagation

\footnotetext{
${ }^{65}$ Currie, Image and Mind, 44.

${ }^{66}$ Currie, Image and Mind, 47.

${ }^{67}$ Gregory Currie, "Film, Reality, and Illusion," in D. Bordwell \& N. Carroll (eds.), Post-Theory: Reconstructing Film Studies (Madison, WI: University of Wisconsin Press, 1997), 325-344: 338 \& 340.

${ }^{68}$ Kania, "Illusion of Realism," 250.
} 
and outward direction of light by an exhibition device. ${ }^{69}$ I mentioned that Ponech restricts his interest to mechanically-generated motion pictures, but I want to note two points about the similarity of the experiences of watching The Searchers and being held prisoner in Plato's cave. First, while there is no exhibition device as such in the cave the shadow puppeteers (unwittingly in the allegory) make use of the projection of light by the fire to generate representations on the wall. The shadows appear to move and although there are no pixels in the sense that Ponech employs there are picture elements, which is how he defines pixels: 'technical jargon for "picture elements", 70 Second, although Ponech uses stroboscopic motion to describe motion on analogue and digital screens, it is also described as the continuous transformations a display undergoes, transformations partly constitutive of itwhich applies to the transformations of shadows on the cave wall as much as the television screen on which The Searchers appears. Matching the combination of the broader senses of picture element and continuous transformations is a broader sense of singletons, which Ponech characterises as 'individuals which undergo objective displacement. ${ }^{\text {71 }}$ The prisoners see individual shadows distinct from other shadows and from the cave wall itself and these shadows appear to move (and make sounds). With these broader delineations in mind, if one considers flip-books as an example of handmade cinematic representations, the displays once again seem to involve individuals who appear to move albeit without an exhibition device propagating and outwardly directing light.

In his essay on Henri Bergson's theory of cinematic motion (which is only tangentially relevant to the illusionism question), Gunning approaches the issue from a perspective distinct from both Bergson and Deleuze on the one hand and cinematic aesthetics on the

\footnotetext{
${ }^{69}$ Ponech, "External Realism," 356.

70 Ponech, "External Realism," 356fn.16.

${ }^{71}$ Ponech, "External Realism," 357 \& 366.
} 
other, employing the concept of animation. ${ }^{72}$ Cinematic animation is 'the technological production of images in motion. Thus all cinema can be approached as animation. ${ }^{, 73}$ The two essential elements of animation are: (a) the perception of motion (b) achieved by technological means. Gunning employs perception rather than illusion for the reasons noted in $\S 3$ and proposes a broad understanding of technological:

This may sound obvious and even tautological, but I would point out the key term here, technological, as something generally taken for granted, indeed rendered invisible, in realist accounts of the moving image. The technological aspect can be deceptively simple (as in the flip book) or the product of complex technical elaboration (as in computer-generated imagery). It refers to a control of the presentation of images at specific thresholds of speed so as to affect their visual perception. ${ }^{74}$

Gunning's concern is film theory's dual failure to recognise the significance of cinematic motion to cinematic art and failure to account for cinematic motion. His approach is useful here as it employs terminology that is neutral between object-generated, handmade, and mechanically-generated cinematic representations such that cinematic animation can take the place of stroboscopic motion. As such, Ponech's argument can be reconstituted for cinematic motion, rather than for mechanically-generated cinematic motion, in the following terms:

(i) The essential properties of cinematic displays are picture elements and animation.

(ii) The combination of picture elements and animation in the cinematic display generates cinematic singletons, which cannot be reduced to their constituents.

\footnotetext{
${ }^{72}$ For Bergson's discussion of cinema, see: Henri Bergson, Creative Evolution, trans. Arthur Mitchell (Lanham, MD: University Press of America, 1984 [1907]).

${ }^{73}$ Gunning, "Paradox of Mechanical Motion," 2.

${ }^{74}$ Gunning, "Paradox of Mechanical Motion," 3-4.
} 
(iii) Cinematic singletons undergo continuous animated displacement, i.e. objective displacement within the cinematic display.

Set in this more inclusive terminology, there are two objections to Ponech, one that challenges the existence of cinematic singletons (Kania) and another that challenges the continuous animated displacement (Gaut).

\section{Cinematic Singletons?}

Kania's response to Ponech would simply deny cinematic motion on the basis that gardenvariety motion requires an object. Kania does not insist on a physical object rather than an object of perception, he simply denies that there is anything - physical or otherwise - to move: there 'is no single reidentifiable image which is moving. ${ }^{75}$ This is the purpose his John Wayne walking example serves. When one experiences the shot frame by frame one sees that the individual images that constitute Ponech's $W-w^{l}$ to $w^{n}-$ are distinct from one another, showing different parts of the actor from different distances and angles, and cannot therefore be identical. Kania would not, however, be able to provide a satisfactory response to Ponech's claim that the frame-by-frame experience is a quasi-cinematic display momentarily deprived of one of its ontological primitives. Cinematic representation is distinguished from related modes of representation as follows: (a) cinematic representations involve pictures rather than people or objects (unlike theatre, including puppetry); and (b) cinematic representations involve real or illusory motion (unlike photography and painting). Regardless of whether that motion is real or illusory it must be experienced in order for the mode of representation to be instantiated. An equivalent case for pictorial representation might be standing so close to a Rembrandt painting that one can discern the texture of the

\footnotetext{
${ }^{75}$ Kania, "Illusion of Realism," 254.
} 
brushstrokes, but not see the shapes that they constitute. The texture of the brushstrokes is partly constitutive of the whole pictorial representation, but does not create an illusion of shape. Gunning's take on the ontological primitives of the cinematic experience is a product of his conception of cinematic animation:

Animation depends not simply on the transformation of still images into motion which Bergson declared impossible (one cannot derive motion from immobilities) but rather on a transformation of perception, a melding of the human sensorium and the machine. ${ }^{76}$

This combination of perception and technology in animation is reminiscent of Deleuze's distinction between the photogramme and the movement-image: cinema does not give us an image to which movement is added, it immediately gives us a movement-image. ${ }^{77}$

For Kania, motion requires something that moves and freezing the frames shows that there is no thing to move. I cannot respond by claiming that cinematic representation simply is representation by means of displays of animated singletons because that would beg the question of whether cinematic motion is real or illusory. My objection is, instead, a reductio ad absurdum. If one allows that a series of isolated components of a particular mode of representation (frozen frames in cinema) is conclusive in determining the ontology of that mode of representation (no identical pictures therefore no singleton), one would be able to reach numerous paradoxical conclusions about familiar modes of representation: not only would individual brushstrokes reveal that there was no (real) shape in pictorial representation, but moments of silence in a musical representation would reveal that there was no (real)

\footnotetext{
${ }^{76}$ Gunning, "Paradox of Mechanical Motion," 7.

77 Delueze was primarily concerned with traditional photochemical film, but his comments on contemporary cartoons illuminate the reciprocal relationship between picture and motion. He claims that cartoons are cinematic rather than pictorial 'because the drawing no longer constitutes a pose or a completed figure, but the description of a figure which is always in the process of being formed or dissolving through the movement of lines and points taken at any-instant-whatevers of their course' (Cinema I, 5).
} 
pitch. The latter example is in fact taken from Kania's own work on musical silence. He identifies four kinds of silence - measured, internal unmeasured, external unmeasured, and quasi-measured - and claims that 'any of these kinds may be an integral part of a larger musical whole. ${ }^{78}$ The isolation of repeated rests, grand pauses, or caesuras does not show that there is no real pitch or sound in the experience of music any more than the isolation of stationary images shows that there is no real singleton in cinema. One could object to my response by claiming that pure music is not usually considered a mode of representation, but the same point could be made about popular music or performed poetry. The frozen frames in The Searchers do not reveal the absence of singletons any more than the caesuras in Milton's Paradise Lost reveal the absence of meter. As such, Kania cannot claim that there is no object that moves.

\section{Cinematic Motion?}

Gaut does not address the question of cinematic singletons, but seems to assume that there is something - a singleton, a particular reidentifiable thing, or a succession of still images - that appears to move. I shall discuss his objection in terms of singletons, noting that if Gaut is read as denying the existence of singletons, then my response to Kania above applies. For Gaut, movement in shadow plays is real, but not movement in flip books or films. His objection to Currie's anti-illusionism is as follows:

Genuine movement is continuous: i.e., things do not jump from one spatial point to another without successively occupying all the intervening points between the start and end points. Yet sequences of cinematic images, i.e. light-patterns on the screen, are not continuous in this sense. So they do not move: they are a succession of still

\footnotetext{
${ }^{78}$ Andrew Kania, "Silent Music," The Journal of Aesthetics and Art Criticism 68 (2010), 343-353: 343.
} 
images. Contrast the case with shadow plays: if I make the shape of a rabbit with my hands in a projector's light, then when the shadow moves, the shadow will occupy all of the intervening points between the start of the sequence and the end. A film of the shadow play might be perceptually indiscriminable from the shadow play, and so would present itself as if the image sequence were continuous: but it would not be continuous, and hence there would be a mere illusion of movement. ${ }^{79}$

Gaut follows his objection with a comment on Currie's likely response, which is that the 'movement of the image supervenes on the pattern of light particles striking the screen.' 80 The idea is that the cinematic singleton (image) possesses properties that the picture elements (pattern of light particles) do not, properties that include movement. Gaut offers a perfunctory dismissal of this non-identity claim before taking Currie to task on a separate but related point about the necessary conditions for genuine movement. Currie holds that 'at each place on the screen occupied by the image as it moves, there should be illumination at that place (and at the relevant time) on the screen', but Gaut notes that audiences spend roughly half their time watching a film in darkness and that the continuous illumination of the screen is illusory. ${ }^{81}$ While this is a conclusive objection to Currie's necessary condition of illumination, it does not address the non-identity claim. Gaut needs to refute only one of the two, however, as Currie's anti-illusionism is dependent upon the combination of non-identity and continuous illumination.

Neither Ponech's stroboscopic motion nor Gunning's cinematic animation nor the hybrid of the two I employed in $\S 5$ require continuous illumination, so Gaut's objection to my position must be on the basis of the non-identity claim, about which all he has to say is: 'I doubt

\footnotetext{
${ }^{79}$ Gaut, Cinematic Art, 65.

${ }^{80}$ Currie, Image and Mind, 40.

${ }^{81}$ Gaut, Cinematic Art, 65; Currie, Image and Mind, 46.
} 
whether Currie's non-identity claim is correct' ${ }^{82}$ Gaut accepts that non-identity between a singleton and its constituent elements would defeat his continuity condition for genuine movement and the question upon which the debate hinges is thus whether the cinematic singleton is identical with its constituents, specifically individual pictures (for handmade cinematic representations) and patterns of light (for mechanically-generated cinematic representations). Gaut's doubt must be weighed against Ponech's account of stroboscopic motion, discussed in $\S 4$ :

Say that $L$ and $L^{n}$ are a metre apart in display space. The stroboscopic event $\left(w^{l},-\right.$, $\left.w^{2}\right) \ldots$ is how $W$ travels between the two locations, in eight seconds, by traversing all of the intervening points along its route in the visual display. All there is to be seen of the singleton's displacement is presented in the display. Stroboscopy advances $W$ from $L$ to $L^{n}$ without eliding any intervening phases and moments of its displacement or arresting its progress. The interval (-) is not an interruption of that movement but, rather, part of the underlying process bringing it about. Of course, $W$ does not move invisibly between flashes. It moves because of them. In normal episodes of continuous stroboscopic displacement, like the one I have been describing, there is an accompanying package of simultaneous transformations to the singleton.

Stroboscopy interacts with subtle structural and other visible differences between $w^{l}$, $w^{2}, \ldots$ Consequently, parts of $W$ change position relative to each other; likewise $W$ and its parts change size, shape, brightness, sharpness, attitude, pitch, and so on. Jointly, $W$ 's displacement and accompanying transformations seem to be the external source of the marvellous impression of smooth, continuous motion that cinema affords spectators. ${ }^{83}$

\footnotetext{
${ }^{82}$ Gaut, Cinematic Art, 65.

${ }^{83}$ Ponech, "External Realism," 365.
} 
If one considers that John Wayne walking in The Searchers could be represented by mechanically-generated cinema (as in Kania's example), object-generated cinema (Wayne in Plato's cave), or handmade cinema (a flip-book of the narrative), the singleton $W$ is generated by the combination of the picture (photograph, shadow, or drawing) with the animation (stroboscopy, walking, or page-turning) in the cinematic display (screen, wall, book). In the cases of the mechanically-generated and handmade cinematic representations respectively, $W$ does not move invisibly during the flashes and flippings, it moves because of them. Ponech claims that his account supports the thesis that cinematic motion is neither merely illusory (contra Kania) nor merely veridical (contra Currie), but objective displacement within the cinematic display - or continuous animated displacement in my hybrid version. ${ }^{84}$

My view is that Ponech's positive account of cinematic motion is more compelling than Gaut's doubt about non-identity, but for those who are not convinced I shall conclude my response to Gaut with an indirect, but perhaps more momentous, objection. In $\S 2$ I made my agreement with Gaut's ontology of film clear: despite the apparently great differences in the experiences of reading one of Bovril's advertising flip-books and watching Alejandro G. Iñárritu's The Revenant (2015), both are experiences of cinematic representation. ${ }^{85}$ Gaut's reconceptualization of cinematic representation is valuable in severing cinematic representation from the photographic representation with which it was often conflated in the twentieth century and in placing the digital revolution in cinema in perspective, revealing that it is not a new mode of representation, but a return to the pre-photographic salience of the picture in cinema. If I am right, then Gaut has made a major contribution to film theory and

\footnotetext{
${ }^{84}$ Ponech, "External Realism," 365.

85 The former can be viewed on the FLIPBOOK.info website (which provides information on close to nine thousand flip-books, flick books, thumb books, and folioscopes) and is available at: $<$ http://www.flipbook.info/index_en.php $>$. For an amusing combination of these two experiences, see: The Flippist, "Leonardo DiCaprio gets his Oscar," Creative Bloq, 14 March 2016 (accessed 20 January 2018), $<$ http://www.creativebloq.com/illustration/flip-book-animations-12121459>.
} 
cinematic aesthetics by showing that there is no essential distinction among object-generated, handmade, and mechanically-generated cinematic representations. If Gaut's illusionism is right, then object-generated cinema is distinct from the other two categories in one of its two main elements and I think this is dangerous ground for the ontology that forms the basis of his philosophy of cinema. Gaut would of course respond by claiming that the experience of motion is the same in all three cases, using his example of a film of a shadow play being perceptually indiscriminable from the shadow play quoted above. Having argued that objectgenerated, handmade, and mechanically-generated displays of moving pictures are all cinematic representations, however, it seems to invite objection to state that while all three categories involve pictures, the other essential element - motion - is ontologically different among them. In other words, Gaut can safely refute Currie's continuous illumination, but the refutation of non-identity has the potential to unravel his own cinematic ontology and perhaps even his philosophy of cinema.

My defence of anti-illusionism has taken the following form:

(i) Cinematic representation occurs by means of cinematic displays.

(ii) The essential properties of cinematic displays are picture elements and animation.

(iii) The combination of picture elements and animation in the cinematic display generates cinematic singletons, which cannot be reduced to their constituents.

(iv) Cinematic singletons undergo continuous animated displacement, i.e. objective displacement within the cinematic display.

(v) Objective displacement within the cinematic display is inconsistent with the creation of an illusion in the minds of spectators. 
(vi) Therefore cinematic motion is real rather than illusory.

One might well ask if and why the question of cinematic motion is significant. My view is that cinematic representation is characteristically realistic, i.e. that cinematic representation has the potential for all of content realism, photorealism, ontological realism, epistemic realism, perceptual realism (discussed in $\S 2$ ), and anti-illusionism (discussed in $\S \S 3-7)$. Antiillusionism, or the reality of cinematic motion, is thus a component of the characteristic realism of cinematic representation. Once again, one may ask if and why the question of cinematic realism understood in terms of the characteristic realism of cinematic representation is significant. The most substantial reason is the relationship between realistic representation and cognitive value. Broadly speaking, a representation is cognitively valuable to the extent that it provides knowledge of the world as it is in itself, a description that is relevant to all six of the components of characteristic realism. The potential for the cognitive impact of cinematic representation has increased exponentially with the development of digital technology from the desktop to the laptop to the handheld device and with the increasing availability and use of that technology. Ironically, given the first appearance of cinematic representation in philosophy, the mode may be the most effective means of education available to philosophers in the twenty-first century. The argument for characteristic cinematic realism is beyond the scope of this paper, however, so I rest my case with the more modest argument for cinematic realism as anti-illusionism, i.e. cinematic motion is real. 